\title{
Modeling Learner Satisfaction in an Electronic Instrumentation and Measurement Course Using Structural Equation Models
}

\author{
Sergio L. Toral, Federico Barrero, Maria R. Martínez-Torres, Sergio Gallardo, and Mario J. Durán
}

\begin{abstract}
The prevailing tendency in modern university reforms is towards "how people learn," following a learner-centered approach in which the learner is the main actor of the teaching-learning process. As a consequence, one of the key indicators of the teaching-learning process is the measurement of learner satisfaction within the classroom. Learner satisfaction has traditionally been measured using survey responses to a standard learning survey. However, more scientific analysis should be performed to assess adequately not only learner satisfaction but also the main dimensions that have a positive impact on learner satisfaction. The purpose of this paper is to define a structural and measurement model in which causal relationships among these different dimensions are adequately established. The methodology is based on a multivariate regression model (Structural Equation Models) to establish scientifically a structural model for learner satisfaction within a classroom, measuring its validity and reliability. The proposed approach has been applied to model learner satisfaction in an electronic instrumentation course at the University of Seville, Spain. The results and implications of this study will contribute to improve student satisfaction with respect to the dimensions considered.
\end{abstract}

Index Terms-Educational technology, electronic equipment, laboratories, learning systems, planning.

\section{INTRODUCTION}

$\mathbf{T}$ HE notion of learner-centered education has been in existence for a long time [1], [2]. Nevertheless, this concept is reemerging in the European countries due to reforms that are to be implemented in 2010 inside the European Higher Education Area (EHEA) [3]-[5]. Learner-centered practices move the focus from the teacher to the student, paying more attention to the learning performance rather than the instruction methodology. Instruction based on a learner-centered framework provides opportunities for learners to draw on their own experiences and interpretations of the learning process [6]-[9]. These practices regard learning as a lifelong process rather than as a process that takes place only in one's youth, following the trend of the majority of current higher education reforms [10]-[12].
In accordance with this approach, learning is considered as a constructive process. Furthermore, as learning is more meaningful and relevant to the student, teaching efficiency is also increased. This effect is particularly important in subjects with a high practical work content in which the skills and abilities of learners need to be improved, especially when students get involved in the learning process, assuming responsibility for their own progress [13]. However, the teaching process should be centered not only on the learner's activities, but also on the learner's satisfaction, taking into account what is relevant for the student. The implementation of learner-centered methodologies demands a prior analysis of the subject, both to understand what is relevant for the student and to identify the dimensions having a higher influence on learner satisfaction.

Satisfaction relates to perceptions of being able to achieve success, and feelings about the achieved outcomes [14], [15]. From this perspective, several studies have explored student satisfaction to improve course planning [9], [16]. Sometimes, these studies are limited to one-dimensional post-training perceptions of learners [17], [18]. Operationally, learner satisfaction is too often measured with "happy sheets" which ask learners to rate how satisfied they were with their overall learning experience. However, the notion of learner satisfaction must be explored through a multidimensional analysis that considers a wide variety of critical dimensions, so as to provide effective metrics that guide improvements in instructional design.

Learner satisfaction scales have been used to assess teaching quality within Information Systems research. User information satisfaction (UIS) and end-user computing satisfaction (EUCS) instruments are examples of user satisfaction scales [19]. Both of them measure several teaching quality factors with a varying number of survey items for each factor [20], [21]. The main drawback of these methods is that they are primarily focused on teaching quality antecedents of learner satisfaction, instead of considering the learner as the main antecedent. This consideration is of particular importance in lab subjects or in asynchronous learning activities, where the role of the lecturer essentially consists of encouraging students' initiative and motivation to obtain a high learning performance. In these contexts, now being promoted in the EHEA, the content is not so as important as are the new competencies (combination of knowledge, skills and attitude) that the students should develop [22].

To assess the extent and specific nature of learner satisfaction, different dimensions should be theoretically and operationally defined. Actually, many studies have been conducted on this topic, employing learner dimensions as antecedents. These 
studies focus on prior learner experiences in e-learning courses [23]-[25], on learner attitudes towards computers [26], [27], on learner computer anxiety [28], on learner Internet self-efficacy [29], and on learner initial computer skills [30].

The purpose of this paper is not only to identify the antecedents of learner satisfaction, but also to define a structural and measurement model in which causal relationships among the different dimensions are adequately established. The starting point was the curriculum redesign of an electronic instrumentation and measurement course [25], where the antecedents of learner satisfaction were identified. These antecedents will be included in a general model to highlight the relationship among the different dimensions previously identified. The appropriate methodology to perform this task is Structural Equation Modeling (SEM).

SEM grows out of, and serves purposes similar to multiple regression, but in a more powerful way. SEM allows modeling of the relationships between multiple independent and dependent dimensions simultaneously, while regression models can analyze only one layer of linkages between independent and dependent dimensions at a time. Therefore, SEM may be used as a more powerful alternative to multiple regression, path analysis, factor analysis, time series analysis, and analysis of covariance. While complex interrelationships cannot be fully explored by these techniques, SEM has the advantage of dissecting these relationships, assessing the total effects of variables on one another. Additionally, SEM provides the associations between variables and estimates the strengths of these relationships in an integrated model [31]. The principle adopted by SEM is based on determining model parameters so as to replicate in the best possible manner the covariance matrix of the dimensions in the model system. This approach facilitates the estimation of complex model systems, determining causal relationships among a set of dimensions, which may include ordinal response variables as well as continuous measurements [32]. SEM has been successfully used in several disciplines including, for example, sociology, psychology or marketing [33]. In the field of educational sciences, SEM has been applied to develop acceptance models [34] or to assess e-learning tools [35]. This study extends the use of SEM to learning satisfaction modeling following a similar procedure.

The paper is structured as follows. Section II describes the existing methods for evaluating learner satisfaction, particularly in a laboratory or practical learning environment, and gives the results obtained from a case study, an electronic instrumentation and measurement course offered by the University of Seville. Section III illustrates the proposed SEM-based methodology for validating the learner satisfaction model. Section IV discusses results and implications and, finally, conclusions are drawn in Section IV.

\section{LEARNER SATiSfaction MEASUREMENT In LABORATORY TEACHING: A CASE STUdY}

Traditionally, measurement of learner satisfaction has been applied to assess information and management systems, including classroom teaching in traditional educational contexts [20], [32], [36]. This measurement should not be evaluated using a single-item scale, such as global satisfaction, and should incorporate different aspects of learner satisfaction, if it is to become a useful diagnostic instrument. Moreover, a learner satisfaction measurement developed for traditional educational contexts is not appropriate for a laboratory or practical learning environment, where the role of the student is completely different to that of a student in a lecture [19]. For instance, the degree of the student participation and initiative, the way in which the educational material is delivered, and the possibilities for feedback and interaction with physical instrumentation are quite different in a laboratory environment. As learner satisfaction is an antecedent of use intention [37], there is a need to develop a comprehensive instrument for measuring learner satisfaction within a practical or laboratory context [19], [25].

In [25], a recently developed comprehensive instrument for measuring learner satisfaction within a practical or laboratory context is described. A course offered during the final semester of the Telecommunication Engineering degree at the University of Seville, "Electronic Instrumentation and Measurement Lab," is used as a case study. This optional course consists of 7.5 Spanish-credits or $75 \mathrm{~h}$, one Spanish-credit being equivalent to $10 \mathrm{~h}$ of lessons. The Telecommunication Engineering degree is organized in five academic years with every year being divided into two semesters. The courses usually last one semester and most of them consist of six credits on average. The lab course analyzed here is taught in the second semester of the final year, and every year about 60 to 90 students enroll in the course. The main goal of the course is to provide students with an understanding of the operating principles and applications of a selected range of basic and advanced instruments, such as logic analyzers, oscilloscopes, spectrum analyzers, LCR meters, etc., while improving students' skills through laboratory work experience. The lab work is based on a "hands on" instruction focus on engineering topics such as modulation techniques, microprocessors systems analysis, reflectometry principles, fixed telephone basics, instrumentation buses, and so on. The students learn about instruments and lab equipment by using them for the analysis of interesting electronic engineering systems and principles. The course also enables students to strengthen other important abilities, in areas such as collaborative work, innovation and research skills.

The course is organized in two separate lab groups, with 30 to 45 students per group. Group "A" takes place on Thursdays, from 4 PM to 9 PM. Group "B" takes place on Fridays, from 9 AM to 2 PM. The students, working in groups of two or three, have to attend to twelve of these 5-h lab sessions. Therefore, during the course each student attends 12 sessions, of $5 \mathrm{~h}$ each, and will work at twelve different workbenches. Each workbench is composed of different electronic instruments and prototype boards that students have to use and test, respectively. The 12 lab sessions composing the course are organized as follows.

- Session 1: Design and analysis of elementary dc meters and multimeters as measurement instruments.

- Session 2: Design and analysis of ac meters and multimeters, including the frequency response analysis of the meters and the implementation of elementary half/full bridge ac voltmeters. 
- Session 3: Use of analog and digital oscilloscopes, and familiarization with their basic characteristics. This lab includes the analysis of probes, their characteristics, performance, applications, and limitations.

- Session 4: Introduction to spectrum analyzers and their principles of operation. This lab work is used to describe the operation principles of spectrum analyzers.

- Session 5: Measurement and characterization of passive impedances and filters using Wheatstone Bridges, LCR, and Spectrum Analyzers with tracking generators. The limitations of probes in high frequency applications are also studied to understand their influence on measurement errors.

- Session 6: Introduction to the use of logic analyzers and to the analysis of complex digital electronic and microprocessors systems, including systems and microcontroller interfacing.

- Session 7: Analysis of General Purpose Interface Buses (GPIB) and their application for controlling electronic equipment. GPIB protocol is used to implement virtual and remote instruments.

- Session 8: Analysis of complex analog electronic systems. The lab work is based on the study of audio principles, audio amplifiers classes and their characterization methods.

- Session 9: A detailed description of the electrical time domain reflectometry (ETDR) mechanism, its applications, and a method for interpreting ETDR signal waveforms are presented.

- Session 10: Introduction to basic telephony concepts and fundamentals. In this lab work, learners study line telephone communications principles and analyze a real telephone prototype.

- Session 11: Description of other digital modulation techniques like FM and FSK, and their applications. FM and FSK modulation techniques are analyzed in the time and frequency domains.

- Session 12: Analysis of advanced electronic digital systems (like digital signal processors or DSP) and protocols (like internal Personal Computers architecture) using logic analyzers.

Previous reading is required to understand the principles of operation of the equipment and instruments to be used in each session. Before beginning the laboratory, instrument handbooks and a detailed handout of each task are available to the students. No formal reports are required of students to evaluate their work, but they have to answer on-the-spot questions during each laboratory session.

To assess the extent and the specific nature of learner satisfaction, the different dimensions, and a structural and measurement model taking into account these dimensions, must be defined. Up to 10 dimensions, shown in Table I, were considered in order to assess learner satisfaction in the prior study [25]. The selection of dimensions was based on the technological acceptance model [38], because satisfaction is generally considered a central mediator of learner behavior. Most behavior researchers would agree that satisfaction influences future usage intention and complaining behavior. Students with high levels of satis-
TABLE I

DIMENSIONS OF LEARNER SATISFACTION

\begin{tabular}{|c|c|}
\hline Content (CON) & Enthusiasm and Motivation (EAM) \\
\hline User interface (UI) & Learning community (LC) \\
\hline Feedback (FED) & Learner responsibility (LR) \\
\hline User control and interactivity (UCI) & Previous Experience (PE) \\
\hline Ease of use (EOU) & Satisfaction (S) \\
\hline
\end{tabular}

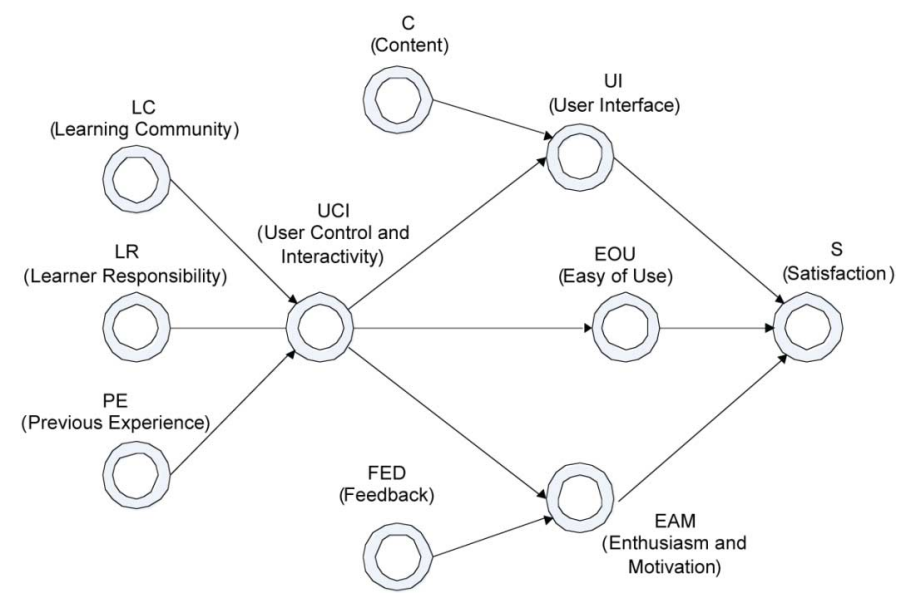

Fig. 1. Learner satisfaction model.

faction are expected to have higher levels of reuse intention and make fewer complaints [37].

A survey based on these dimensions was applied to the course in order to improve its organization in accordance with learner satisfaction measurements. The results obtained highlighted those dimensions with a higher influence on learner satisfaction, showing that content, user interface, ease of use, and motivation were the most appropriate to be reinforced. According to this analysis, the course was redesigned, and postimplementation results were obtained to show the improvements in the students' development. Although the experimental results obtained clearly showed such an improvement, the resulting model was very simple. All the dimensions were correlated with learner satisfaction, and the correlation value was used in the analysis. Nevertheless, no interrelationships between the dimensions considered were analyzed. These interrelationships should be considered, as the correlation matrix shows that there are strong correlations between several of the dimensions, and these correlations can modify the real impact on learner satisfaction. As a consequence, the methodology had to be modified from that the one used in [25]. Specifically, SEM is applied in this case in order to validate a final model considering the dimensions listed in Table I.

\section{LEARNing SATISFAction Model VALIDATION USING SEM}

The model to be validated is shown in Fig. 1. The dimension on the right side is satisfaction, directly driven by the user interface, ease of use, enthusiasm and motivation, and indirectly driven by the rest of dimensions. The dimensions on the left side are the pure independent variables, while the intermediate dimensions are dependent variables that may act as an indepen- 
TABLE II

VALIDATED SURVEY BASED ON THE LEARNER SATISFACTION DIMENSIONS

\begin{tabular}{|c|c|c|}
\hline $\begin{array}{l}\text { Dimension } \\
\text { (Reliability) }\end{array}$ & & Item (Correlation item-dimension) \\
\hline \multirow{5}{*}{$\begin{array}{l}\text { Content } \\
(0.8642)\end{array}$} & 11 & $\begin{array}{l}\text { The material provided for the use of the lab equipment is useful for learning the } \\
\text { concepts related to this practical work }(0.7452)\end{array}$ \\
\hline & 12 & The material needed for the lab work is clear and sufficient $(0.7584)$ \\
\hline & 13 & $\begin{array}{l}\text { The material provided for the lab work is useful for learning the concepts related } \\
\text { to this practical work }(0.7604)\end{array}$ \\
\hline & 14 & My understanding level after the practical work is good (0.6632) \\
\hline & 15 & Practical work is based on real examples (0.5099) \\
\hline \multirow{3}{*}{$\begin{array}{l}\text { User interface } \\
\quad(0.8068)\end{array}$} & 16 & $\begin{array}{l}\text { The available tools and resources for implementing the practical work are } \\
\text { appropriate for the successful implementation of the required work }(0.6070)\end{array}$ \\
\hline & 17 & Learning necessities are covered by the practical work (0.6799) \\
\hline & 18 & $\begin{array}{l}\text { Learning performance is improved due to the variety of equipments and devices } \\
\text { used during the required work }(0.6732)\end{array}$ \\
\hline \multirow{3}{*}{$\begin{array}{l}\text { Feedback } \\
(0.6734)\end{array}$} & 19 & $\begin{array}{l}\text { Feedback given information is useful in solving the difficulties encountered } \\
\text { during the implementation of the practical work }(0.5484)\end{array}$ \\
\hline & 110 & $\begin{array}{l}\text { Students receive the necessary instructions to accomplish the practical work } \\
(0.6842)\end{array}$ \\
\hline & 111 & $\begin{array}{l}\text { The professorship is accessible and ready to help with questions or problems } \\
(0.5851)\end{array}$ \\
\hline \multirow{4}{*}{$\begin{array}{c}\text { User control } \\
\text { and } \\
\text { interactivity } \\
(0.8294)\end{array}$} & I12 & The practical work allows my active participation (0.6244) \\
\hline & 113 & $\begin{array}{l}\text { Students are free to use whatever equipment (related to the practical work) that } \\
\text { they consider to be necessary }(0.7389)\end{array}$ \\
\hline & 114 & $\begin{array}{l}\text { Students have access to all the necessary reference material during the } \\
\text { practical work }(0.5949)\end{array}$ \\
\hline & 115 & $\begin{array}{l}\text { Students are free to setup and try out different options while performing the } \\
\text { practical work }(0.6658)\end{array}$ \\
\hline \multirow{5}{*}{$\begin{array}{l}\text { Ease of use } \\
\quad(0.8272)\end{array}$} & I16 & The practical work can be performed easily $(0.6684)$ \\
\hline & 117 & $\begin{array}{l}\text { The knowledge to carry out the practical work is appropriate to the students' } \\
\text { formative level }(0.6948)\end{array}$ \\
\hline & 118 & $\begin{array}{l}\text { Both, the laboratory equipment and the test bench equipment were reliable } \\
(0.5411)\end{array}$ \\
\hline & I19 & The lab test bench is easy to use (0.6799) \\
\hline & 120 & Adequate time was allowed to complete the practical work $(0.5345)$ \\
\hline \multirow{3}{*}{$\begin{array}{l}\text { Enthusiasm } \\
\text { and Motivation } \\
(0.8300)\end{array}$} & 121 & The motivation imparted by the instructors to learn the material is high $(0.5985)$ \\
\hline & 122 & I enjoy carrying out the practical work (0.7574) \\
\hline & 123 & $\begin{array}{l}\text { Performing the realization of the practical work is a motivating experience } \\
(0.7234)\end{array}$ \\
\hline \multirow{2}{*}{$\begin{array}{l}\text { Learning } \\
\text { community } \\
(0.7134)\end{array}$} & 124 & $\begin{array}{l}\text { I feel as a part of a project team while performing the realization of the practical } \\
\text { work }(0.5544)\end{array}$ \\
\hline & 125 & $\begin{array}{l}\text { I assume responsibilities while performing practical work in the assembly and } \\
\text { test of the practice }(0.5544)\end{array}$ \\
\hline \multirow{2}{*}{$\begin{array}{c}\text { Learner } \\
\text { responsibility } \\
(0.6847)\end{array}$} & 126 & $\begin{array}{l}\text { I usually solve the difficulties that arise during the lab work on my own initiative } \\
(0.5206)\end{array}$ \\
\hline & 127 & My participation contributed to the success of the lab work (0.5206) \\
\hline \multirow{4}{*}{$\begin{array}{c}\text { Previous } \\
\text { experience } \\
(0.8134)\end{array}$} & 128 & According to my previous experience, I enjoy practical classes $(0.6824)$ \\
\hline & 129 & Practical work always improves my learning performance $(0.7145)$ \\
\hline & 130 & I usually overcome the difficulties encountered during the practical work $(0.5571)$ \\
\hline & 131 & $\begin{array}{l}\text { The quality of the practical work previously performed in the past was high } \\
(0.5895)\end{array}$ \\
\hline \multirow{4}{*}{$\begin{array}{l}\text { Satisfaction } \\
\quad(0.8424)\end{array}$} & 132 & $\begin{array}{l}\text { Overall, I consider the practical work a positive experience for improving my } \\
\text { learning performance }(0.6467)\end{array}$ \\
\hline & 133 & The material available for the practical work is good $(0.6978)$ \\
\hline & 134 & The equipment supplied for the practical work is good $(0.6930)$ \\
\hline & 135 & I am satisfied with implementation of this practical work (0.6701) \\
\hline
\end{tabular}

dent variable with respect to one other. In contrast with classical regression models, SEM hypothesizes that dimensions such as those aforementioned are not directly observable, and are better modeled as latent rather than observable variables. As a consequence, they are indirectly measured through a set of indicators. In this way, SEM makes it possible to distinguish two different types of errors: errors in equations, as shown by the path model, and errors in the observation of variables [39].

The validated questionnaire presented in [25] and Table II, was also employed here, and was distributed to and completed by 284 students enrolled in the Electronic Instrumentation and Measurement Lab course. Each dimension is measured using 
several indicators. Cronbach's alpha index (a reliability index associated with the variation accounted for by the true score of the "underlying dimension") was used to prove the reliability of the questionnaire. This coefficient ranges from 0 to 1 . The higher the score, the more reliable is the generated scale. A value above 0.7 is an acceptable reliability coefficient, although lower thresholds are sometimes used in [40]. Table II shows the reliability analysis results, including the value of Cronbach's alpha given in parentheses under the dimension. The inter-item correlation associated with each item is also shown in the second column of Table II between parentheses. Thirty-three of the questions, the majority, report satisfactory values. Items I5 and I20 were rejected due to the low interitem correlation value.

Once the set of items for measuring the underlying dimension has been defined, the hypothesis of the proposed model will be validated. If the model is analyzed from right to left (Fig. 1), it can be concluded that satisfaction (S) is primarily driven by the User Interface (UI), Ease of Use (EOU), and Enthusiasm and Motivation (EAM). UI and EOU are related to the quality and effectiveness of the instructor and the instruction (cognitive dimension) while EAM locates the instructor as a facilitator of knowledge and capabilities transmission (affective dimension). Consequently, satisfaction is achieved as a mixture of cognitive and affective dimensions. Although instructors tend to improve only cognitive dimensions, affective dimensions should also be considered because they promote positive feelings towards the subject.

A clear antecedent of these three dimensions is User Control and Interactivity (UCI). Indeed, UCI must be facilitated by the way in which content is delivered (User Interface), which should work both reliably and conveniently (Ease of Use). At the same time, User Control and Interactivity also encourages students to participate actively in the practical work. As shown in Fig. 1, this dimension is the central element in the model. UCI is stimulated by three independent dimensions and drives the three dimensions with a direct influence over satisfaction. Going from left to right of the model, five pure independent dimensions can be mentioned. Learning community (LC), learner responsibility (LR), and previous experience (PE) are the three dimensions that show the student's profile. These three represent an input to the course and, consequently, they can be considered as independent variables in the proposed model. User Control and Interactivity is determined by the student profile. However, the instructor is responsible for guiding the student's initiative and increasing the user satisfaction.

The last two pure independent variables are content $(\mathrm{CON})$, related to the quality and effectiveness of the knowledge transmission, and feedback (FED), related to the strengthening of users' learning via verification (affective dimension). Neither of these variables have a direct influence over satisfaction. The first is modulated by the user interface, the way in which this content is delivered (cognitive dimension). The second is modulated by the enthusiasm and motivation of students when performing the practical work (affective dimension).

Other dimensions could be considered, but the inclusion of too many dimensions could cause undesirable effects, such as model overfit.
Once the model has been described, the next step is to validate it. The confirmatory structural and measurement model is obtained and validated using SEM. According to [40], if SEM is accurately applied it can surpass such first-generation techniques as Principle Components Analysis, Factor Analysis, Discriminant Analysis, or Multiple Regressions. Specifically, SEM provides a greater flexibility in estimating relationships among multiple predictors and criterion variables, and allows modeling with unobservable latent variables. Additionally, SEM estimates the model without contamination from measurement errors. The two approaches to causal modeling which appear in the literature are as follows.

- Partial Least Square (PLS). The PLS method [40] is a Structural Model Equation modeling technique widely used in social sciences and business research [41]-[44], and PLS regression is an extension of the multiple linear regression models. In its simplest form, a linear model specifies the (linear) relationship between a dependent variable (the use of the tool), and a set of predictor variables (external variables previously obtained). The objective in PLS is to maximize the explanation variance. Thus, $\mathrm{R}^{2}$ and the significance of the relationships among variables or dimensions are measures that indicate how well a model is performing. The conceptual core of PLS is an iterative combination of Principal Component Analysis relating items to dimensions, and path analysis permitting the construction of a causal model. The hypothesizing of relationships between dimensions and items, and among different dimensions is guided by the previous literature in this field. The estimation of the parameters representing the measurement and path relationships is accomplished using Ordinary Least Squares (OLS) techniques.

- Covariance structure analysis as implemented in the Linear Structural Relations (LISREL) model. LISREL estimates model parameters in an attempt to reproduce the covariance matrix of the measures (or observable variables), and also incorporates overall goodness-of-fit measures to evaluate how well the hypothesized model "fits" the data. Covariance structure analysis is "theory-oriented, and emphasizes the transition from exploratory to confirmatory analysis" [45].

The basic distinction between PLS and LISREL as causal modeling methodologies rests in their objectives. LISREL is best used for theory testing and development [45]; while PLS is oriented towards predictive applications [46]. In comparison with LISREL, the objective of PLS is the explanation of variance in a regression sense, and thus $\mathrm{R}^{2}$ and the significance of relationships among dimensions are measures more indicative of how well a model is performing. "PLS is primarily intended for causal-predictive analysis in situations of high complexity, but low theoretical information" [45]. For these reasons, model testing was examined through a PLS framework in the present case.

Following the two-step analytical procedure [47], the measurement model is first examined, and then the structural model. The rationale of this two-step approach is to ensure that the conclusion on structural relationship is drawn from a set of measurement instruments with desirable psychometric 
TABLE III

PLS RESULTS

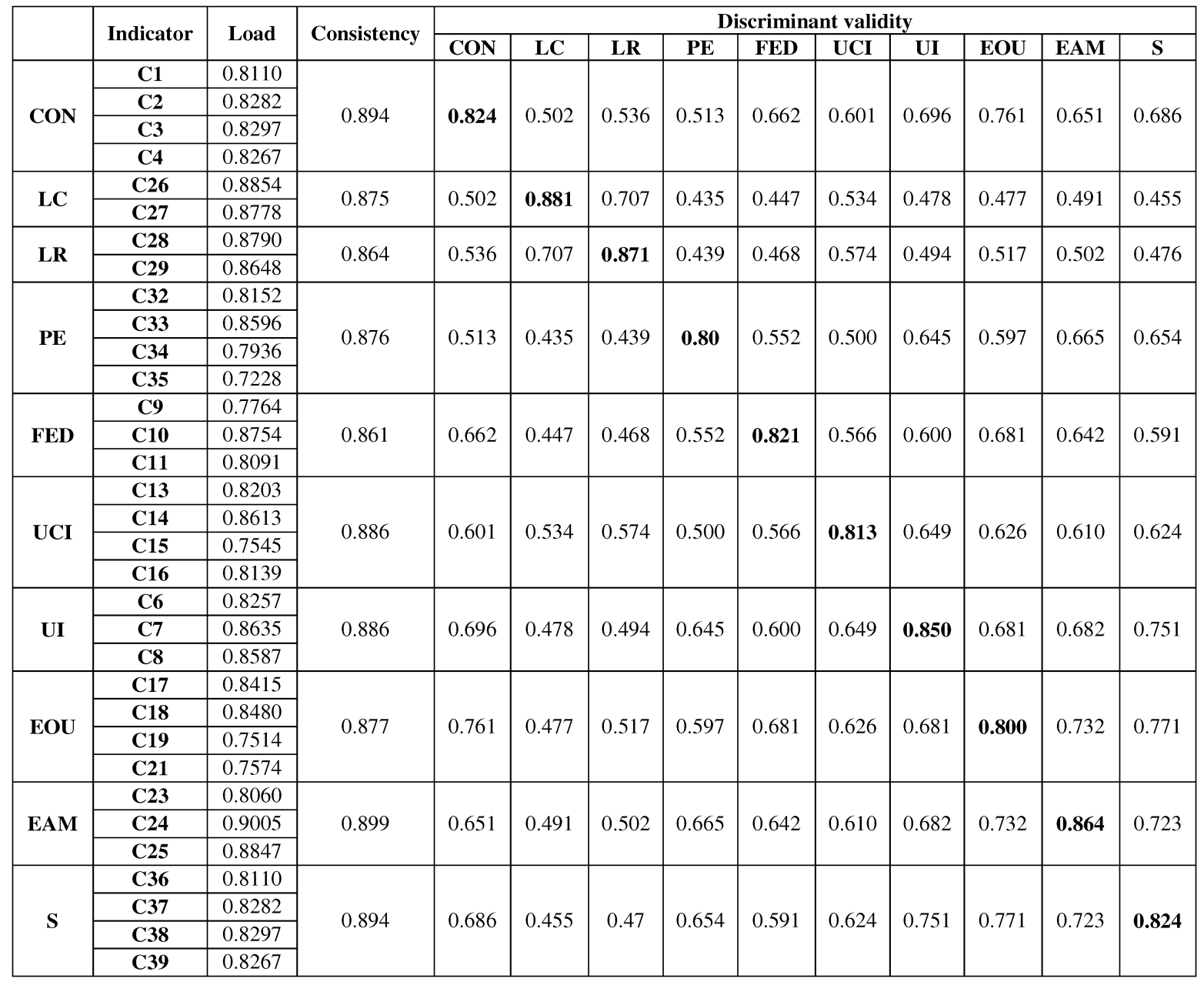

properties. The measurement model is evaluated in terms of reliability, internal consistency, convergent validity, and discriminant validity. Table III summarizes the factor loadings and average variance extracted from the measures of the proposed research model.

- Individual item reliability. In general, one would like to have each indicator sharing more variance with the component score than with the error variance. This condition implies that the square of loadings should be greater than 0.70 . Loadings of 0.5 and 0.6 are acceptable if there are additional indicators in the block for comparison basis [40]. This condition was met in this study, as shown in Table III.

- Convergent validity indicates the extent to which the items of a scale that are theoretically related should have a high correlation. Convergent validity was evaluated for the measurement scales using two criteria suggested by [42]: (1) all indicator factor loadings should be significant and exceed 0.70 and (2) Average Variance Extracted (AVE) for each dimension should exceed the variance due to measurement error for that dimension (i.e., should exceed 0.50 ). All the measures meet the recommended levels (see Table III).
- Discriminant validity is the extent to which the measure is not a reflection of another variable. Discriminant validity is indicated by low correlations between the measure of interest and the measures of other dimensions. Evidence of discriminant validity of the measures can be verified using the squared root of the Average Variance Extracted for each dimension higher than the correlations between it and all other dimensions [42]. As summarized in Table III, the square root of Average Variance Extracted for each dimension (on the diagonal) is greater than the correlations between the dimensions and all other dimensions. The results suggest an adequate discriminant validity of the measurements.

Next, the structural model is examined. The research model was tested using PLS-Graph v.3.0 [48]. The model was estimated using the maximum likelihood method. Fig. 2 depicts fit statistics, overall explanatory power, and estimated path coefficients. To assess the statistical significance of the path coefficients, which are standardized betas, a bootstrap analysis was performed. Bootstrapping provides an estimate of the variability of the parameters in a final model. The use of bootstrapping, as opposed to traditional t-tests, allows the testing of the significance of parameter estimates from data which are not assumed 


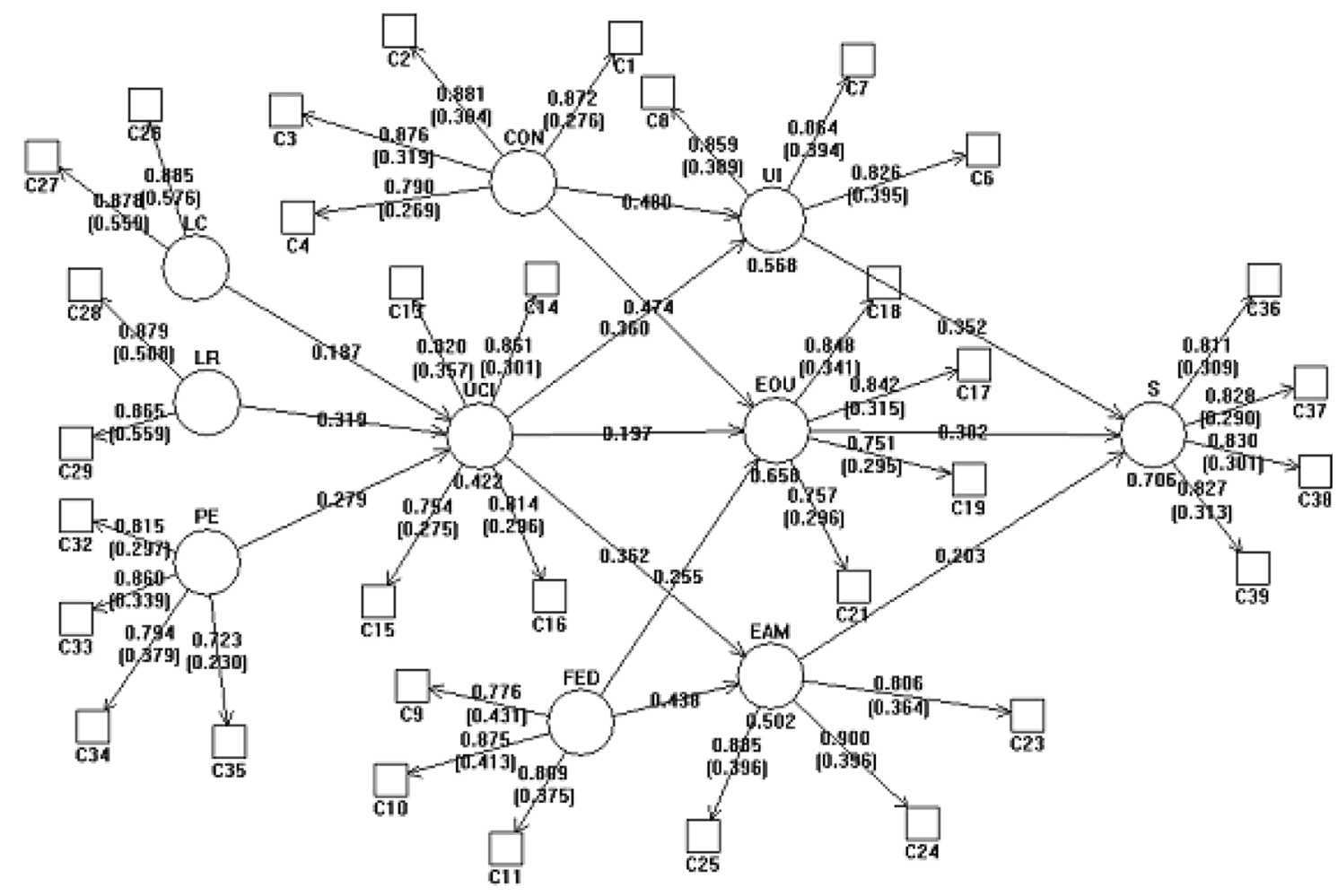

Fig. 2. PLS result: detailed model.

TABLE IV

Path CoefFicients TABLE (T-STATISTIC)

\begin{tabular}{|c|c|c|c|c|c|c|c|c|c|c|}
\hline & CON & LC & LR & PE & FED & UCI & UI & EOU & EAM & S \\
\hline CON & 0.00 & 0.00 & 0.00 & 0.00 & 0.00 & 0.00 & $6.29^{* * *}$ & $6.63^{* * *}$ & $3.73^{* * *}$ & 0.00 \\
\hline LC & 0.00 & 0.00 & 0.00 & 0.00 & 0.00 & 0.00 & 0.00 & 0.00 & 0.00 & 0.00 \\
\hline LR & $10.09^{* * * *}$ & 0.00 & 0.00 & 0.00 & 0.00 & $7.57^{* * * *}$ & 0.00 & 0.00 & 0.00 & 0.00 \\
\hline PE & $8.34^{* * * *}$ & 0.00 & 0.00 & 0.00 & $4.45^{* * *}$ & $3.70^{* * * *}$ & 0.00 & 0.00 & 0.00 & 0.00 \\
\hline FED & 0.00 & 0.00 & 0.00 & 0.00 & $7.16^{* * *}$ & $5.75^{* * * *}$ & 0.00 & 0.00 & 0.00 & 0.00 \\
\hline UCI & 0.00 & 0.00 & 0.00 & 0.00 & 0.00 & 0.00 & 0.00 & 0.00 & 0.00 & 0.00 \\
\hline UI & 0.00 & $2.62^{* * *}$ & $5.08^{* * * *}$ & $5.44^{* * *}$ & 0.00 & 0.00 & 0.00 & 0.00 & 0.00 & 0.00 \\
\hline EOU & 0.00 & 0.00 & 0.00 & 0.00 & 0.00 & 0.00 & 0.00 & 0.00 & 0.00 & 0.00 \\
\hline EAM & 0.00 & 0.00 & 0.00 & 0.00 & 0.00 & 0.00 & 0.00 & 0.00 & 0.00 & 0.00 \\
\hline S & 0.00 & 0.00 & 0.00 & 0.00 & 0.00 & 0.00 & 0.00 & 0.00 & 0.00 & 0.00 \\
\hline
\end{tabular}

${ }^{*} \mathrm{p}<0.05 ;{ }^{* *} \mathrm{p}<0.01 ;{ }^{* * *} \mathrm{p}<0.001, \mathrm{t}(0.05 ; 499)=1.9672 ; \mathrm{t}(0.01 ; 499)=2.5857 ; \mathrm{t}(0.001 ; 499)=3.3101$

to be multivariate normal. Subsamples are automatically generated from the existing data by removing cases from the total data set generated by the 284 students. The number of random subsamples to be generated is set by the analyst. For this study, the number of bootstrap subsamples was set at 500. PLS estimates the parameters of each sub sample and "pseudovalues" are calculated by applying the bootstrap formula. Table IV shows that most of the paths proved to be significant at the p-value $<0.001$ level. All the hypotheses about relationships among dimensions were supported.

Finally, the results from the analysis show the explanatory power of the research model, revealing that the proposed model satisfactorily accounted for $70.6 \%$ of the variance.

In summary, the necessary steps to validate a structural and measurement model are next detailed.

1) Define a model to be validated. The links of the model should be supported by previous studies or works.

2) Design a questionnaire to measure each of the dimensions of the model. Each dimension must be measured by several indicators that can be obtained from a survey of students. The reliability of the questionnaire is then checked using a Cronbach's alpha index, removing those indicators with a low interitem correlation value.

3) Analyze the structural and measurement model using SEM. A structural equation modeling, such as PLS, allows the validation of the indicators of each dimension (measurement model) as well as the hypothesized links (structural model).

a) The measurement is tested using several criteria like individual item reliability, convergent validity and discriminant validity.

b) The structural model is tested using a bootstrap analysis.

\section{RESULTS AND IMPLICATIONS}

According to Fig. 2, the results from the analysis guarantees that the proposed model accounted for $70.6 \%$ of the variance in satisfaction. Consequently, $70.6 \%$ of the variance in students' 
TABLE V

New TEACHING ACTIVITIES AND LEARNING ENVIRONMENTS TO IMPROVE StUdENTS' SATISFACTION

\begin{tabular}{|c|c|}
\hline Dimension & Improvements \\
\hline $\mathrm{CON}$ & $\begin{array}{l}\text { New activities have been programmed in the lab. These activities include practical } \\
\text { exercises to analyze industrial buses and protocols, domotic systems, remote and virtual } \\
\text { instrumentation control and mobile technologies. }\end{array}$ \\
\hline UI & $\begin{array}{l}\text { Application of a new learning management system: } \\
\text { http://edsplab.us.es/docencia/login/index.php (select "entrar como invitado" option and } \\
\text { use the following password "7002eil" to see the actual appearance of the learning } \\
\text { environment). }\end{array}$ \\
\hline EOU & $\begin{array}{l}\text { This dimension is enhanced using multimedia technologies and contents to improve the } \\
\text { learning processes. This novel material, shown in Fig. } 4 \text {, was designed with Shockwave } \\
\text { and Macromedia Director } \\
\text { as } \text {. Explanation is combined with illustrative examples, and online } \\
\text { experiment. A range of media elements are used to convey a given message, and the } \\
\text { students can study at a time and place convenient to them, taking as much long or as little } \\
\text { time as they need. }\end{array}$ \\
\hline EAM & $\begin{array}{l}\text { Use of real world applications to produce visible and motivating results in the lab work. } \\
\text { Development of team cooperation and collaboration skills }\end{array}$ \\
\hline $\mathbf{U C I}$ & $\begin{array}{l}\text { The students are involved in taking decisions during the class. The practical system to be } \\
\text { analysed is presented at the beginning of the class and the students must decide what } \\
\text { must be measured, and how, and which kind of electronic equipment should be used. }\end{array}$ \\
\hline FED & The number of professors attending the class was doubled during the last academic year. \\
\hline
\end{tabular}

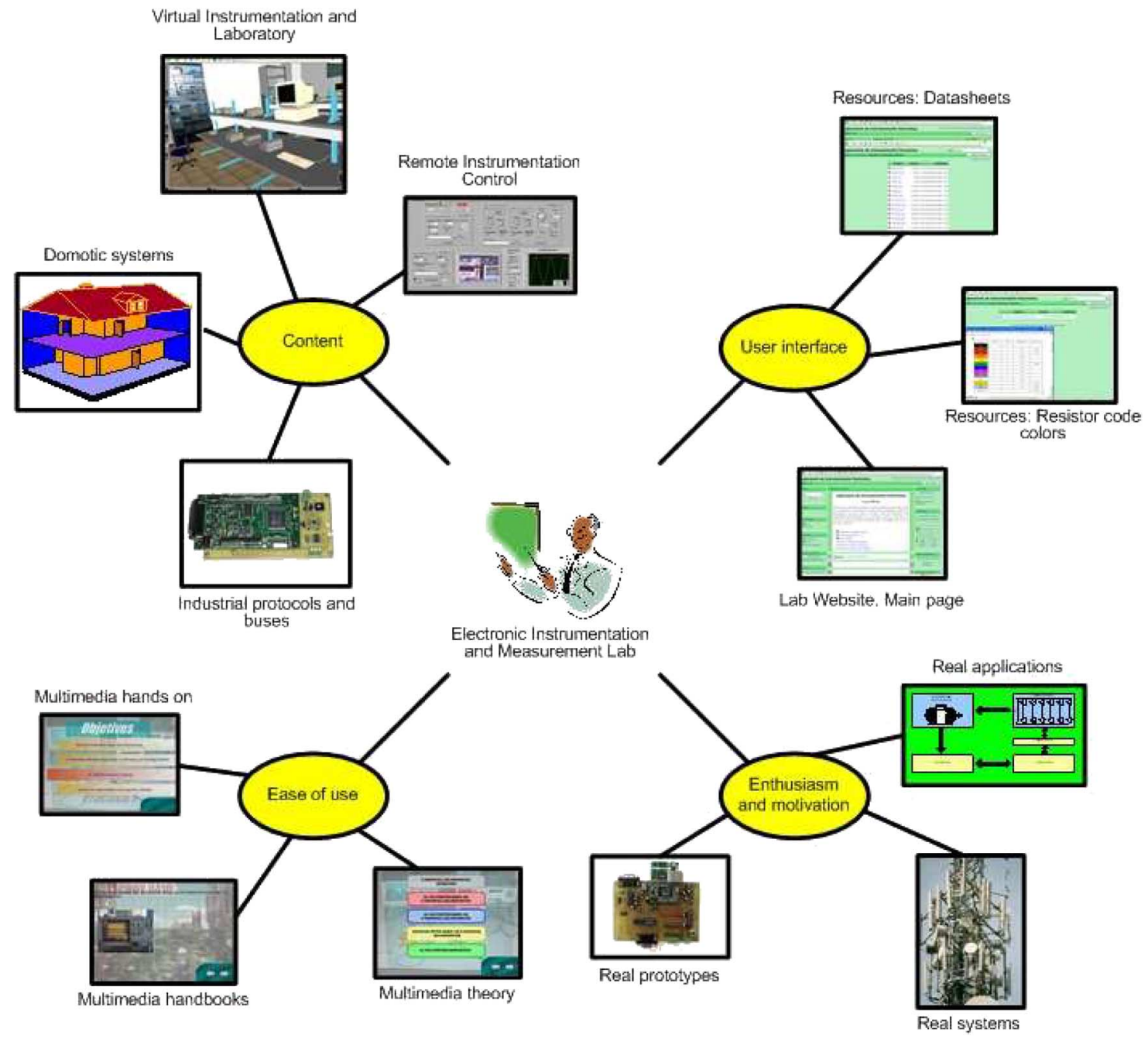

Fig. 3. Improvements on the current course organization according to learner satisfaction measures.

satisfaction can be explained, which is an excellent result for this kind of analysis.
The obtained result corroborates the preliminary study presented in [25]. Topics related to controllable dimensions like 
content, user interface, ease of use, and enthusiasm and motivation must be promoted to improve students' satisfaction. New activities and learning environments can be proposed to improve the content, user interface, ease of use, and enthusiasm and motivation dimensions.

In the case study, the Electronic Instrumentation and Measurement Lab course, the content dimension is improved by planning new activities in the lab, based on industrial buses and protocols, domotic systems, remote and virtual instrumentation control and mobile technologies. The user interface dimension is improved through the application of a learning management system while the ease of use dimension is enhanced using multimedia technologies and contents to improve the learning processes. The enthusiasm and motivation dimension is enhanced using real world applications, with practical results of the developed work. The inclusion of collaborative and cooperative hands-on work improves competences like teamwork and collaboration skills. Finally, the user control and interactivity dimension is improved through students' decision-making during the class, and the feedback dimension is promoted by doubling the number of professors attending each class. These improvements are detailed in Table $\mathrm{V}$ and Fig. 3.

\section{CONCLUSION}

Learner satisfaction has been modeled in an Electronic Instrumentation and Measurement Lab using Structural Equation Models. The adopted approach is based on the learner's satisfaction, according to the current European higher education reforms, where the focus of attention is moving from the teacher to the learner. Students' satisfaction is positively impacted when the content is transmitted through an adequate user interface, when the interaction with instrumentation equipment and tools is easy and adequate to the students' level, and when they feel motivated by the work they are required to do. The model distinguishes five pure independent variables: content and feedback, that should mainly be managed by the lecturer, and the three elements of the students' profile (Learning Community, Learner Responsibility and Previous Experience dimensions), which depend on the attitudes and capabilities of students who attend the course. The management of all of these variables is the responsibility of the lecturer, who must also consider attitudes and capabilities to promote user control and interactivity.

In accordance with the proposed model, satisfaction is the result of two types of influences: the cognitive and the affective influence. Cognitive influence is essentially driven by the upper-middle part of the model, that is, the content of the course and the way it is delivered to students, plus the possibilities of interaction with equipment and tools. The lower-middle part of the model represents the affective influence over satisfaction, that is, students' motivation when working in the lab. User control and interactivity has also an affective component in the sense that it can promote enthusiasm and motivation.

In accordance with this analysis, several improvements regarding the content, user interface, ease of use, and motivation should be considered. Although some other dimensions could be considered, the number of these should be kept low to avoid model overfit. The proposed methodology can be generalized to any subject in a higher education course, and demonstrates its usefulness in highlighting which relevant aspects should be improved from a learner-centered approach.

\section{REFERENCES}

[1] M. Alfassi, "Effects of a learner-centred environment on the academic competence and motivation of students at risk," Learn. Environ. Res., vol. 7, pp. 1-22, 2004.

[2] A. Jones and V. Compton, "Towards a model for teacher development in technology education: From research to practice," Int. J. Technol. Design Educ., vol. 8, pp. 51-65, 1998.

[3] Joint Declaration of the European Ministers of Education, The European Higher Education Area-Bologna Declaration. Bologna, Jun. 19, 1999.

[4] University of Deusto and University of Groningen. Tuning Educational Structures in Europe, Final Report Phase One, J. González and R. Wagenaar, Eds., 2003.

[5] S. L. Toral, M. R. Martínez-Torres, F. Barrero, S. Gallardo, E. Vargas, and V. Gónzalez, "Planning a master's level curriculum according to career space recommendations using concept mapping techniques," Int. J. Technol. Design Educ., vol. 16, no. 3, pp. 237-252, 2006.

[6] E. D. Wagner and B. L. Mccombs, "Learner centered psychological principles in practice: Designs for distance education," Educ. Technol., vol. 35, no. 2, pp. 32-35, 1995.

[7] M. Duran, S. Gallardo, S. Toral, M. R. M. Torres, and F. Barrero, "A learning methodology using Matlab/Simulink for undergraduated electrical engineering courses attending to learner satisfaction outcomes," Int. J. Technol. Design Educ., vol. 17, no. 1, pp. 55-73, 2007.

[8] S. Hadjerrouit, "Learner-centred web-based instruction in software engineering," IEEE Trans. Educ., vol. 48, pp. 99-104, 2005.

[9] J. Milliken and L. P. Barnes, "Teaching and technology in higher education: Student perceptions and personal reflections," Comp. Educ., vol. 39, pp. 223-235, 2002.

[10] J. González and R. Wagenaar, Tuning Educational Structures in Europe II. Universities' Contribution to the Bologna Process Univ. Deusto and Univ. Groningen, 2005.

[11] M. R. Martínez-Torres, F. Barrero, S. L. Toral, and S. Gallardo, "A digital signal processing teaching methodology using concept mapping techniques," IEEE Trans. Educ., vol. 48, no. 3, pp. 422-429, 2005.

[12] S. L. Toral, F. Barrero, M. R. Martínez-Torres, S. Gallardo, and J. Lillo, "Implementation of a web-based educational tool for digital signal processing teaching using the technological acceptance model," IEEE Trans. Educ., vol. 48, no. 4, pp. 632-641, 2005.

[13] N. M. Lambert and B. L. McCombs, How Students Learn: Reforming Schools Through Learner Centred Education. Wash., DC: Amer. Psycholog. Assoc., 1997.

[14] J. M. Keller, "Instructional-design theories and models: An overview of their current status," in Motivational Design of Instruction. Hillsdale, NJ: Lawrence Erlbaum, 1983, pp. 386-434.

[15] E. L. Deci and R. M. Ryan, Handbook of Self-Determination Research. Cambridge, U.K.: Boydell and Brewer, 2002.

[16] S. D. Johnson, S. R. Aragon, N. Shaik, and N. Palma-Rivas, "Comparative analysis of learner satisfaction and learning outcomes in online and face-to-face learning environments," J. Interact. Learn. Res., vol. 11, no. 1, pp. 29-49, 2000.

[17] I. M. Abdel-Qader, B. J. Bazuin, H. S. Mousavinezhad, and J. K. Patrick, "Real-time digital signal processing in the undergraduate curriculum," IEEE Trans. Educ., vol. 46, no. 1, pp. 95-101, 2003.

[18] H. Mousavinezhad and I. Abdel-Qader, "Digital signal processing in theory and practice," in Proc. 2001 Frontiers In Educ. Conf., Reno, NV, Oct. 2001.

[19] Y. S. Wang, "Assessment of learner satisfaction with asynchronous electronic learning systems," Inf. Manage., vol. 41, pp. 75-86, 2003.

[20] W. J. Doll and T. S. Raghunathan, "A confirmatory factor analysis of the user information satisfaction instrument," Inf. Syst. Res., vol. 6, no. 2, pp. 177-188, 2001.

[21] R. McHaney, R. Hightower, and J. Pearson, "A validation of the enduser computing satisfaction instrument in Taiwan," Inf. Manage., vol. 39, pp. 503-511, 2002.

[22] Commision of the European Communities, Nov. 2005, Proposal for a Recommendation of the European Parliament and of the Council on Key Competences for Lifelong Learning [Online]. Available: http://ec. europa.eu/education/policies/2010/doc/keyrec_en.pdf

[23] J. B. Arbaugh, "How instructor immediacy behaviours affect student satisfaction and learning in web-based courses," Business Communication Quarterly, vol. 64, no. 4, pp. 42-54, 2001. 
[24] J. B. Arbaugh, "Managing the on-line classroom: A study of technological and behavioral characteristics of web-based MBA courses," $J$. High Technol. Manage. Res., vol. 13, pp. 203-223, 2002.

[25] S. Gallardo, F. Barrero, M. R. Martínez-Torres, S. L. Toral, and M. J. Durán, "Addressing learner satisfaction outcomes in electronic instrumentation and measurement laboratory course organization," IEEE Trans. Educ., vol. 50, no. 2, pp. 129-136, 2007.

[26] Y. J. Katz, "Attitudes affecting college students' preferences for distance learning," J. Comput. Assisted Learn., vol. 18, pp. 2-9, 2002.

[27] C. L. Dillon and C. N. Gunawardena, "A framework for the evaluation of telecommunications-based distance education," in Proc. 17th Congress Int. Council for Distance Educ., 1995, vol. 2, pp. 348-351, Open Univ.., Milton Keynes.

[28] F. G. Barbeite and E. M. Weiss, "Computer self-efficacy and anxiety scales for an Internet sample: Testing measurement equivalence of existing measures and development of new scales," Comput. Human Behav., vol. 20, pp. 1-15, 2004.

[29] A. Y. Wang and M. H. Newlin, "Predictors of web-student performance: The role of self-efficacy and reasons for taking an on-line class," Comput. Human Behav., vol. 18, no. 2, pp. 151-163, 2002.

[30] A. Sturgill, W. Martin, and G. Gay, "Surviving technology: A study of student use of computer-mediated communication to support technology education," Int. J. Educ. Telecommun., vol. 5, pp. 239-259, 1999.

[31] R. B. Kline, Principles and Practice of Structural Equation Modeling. New York: NY Guilford, 1998.

[32] E. K. Kelloway, "Structural equation modeling in perspective," J. Organiz. Behav., vol. 16, no. 3, pp. 215-224, 1995.

[33] M. R. Martínez-Torres, "A procedure to design a structural and measurement model of intellectual capital: An exploratory study," Inf. Manage., vol. 43, no. 5, pp. 617-626, 2006.

[34] S. L. Toral, F. Barrero, and M. R. Martínez-Torres, "Analysis of utility and use of a web based tool for digital signal processing teaching by means of a technological acceptance model," Comput. Educ., vol. 49, no. 4, pp. 957-975, 2007.

[35] K. A. Pituch and Y.-K. Lee, "The influence of system characteristics on e-learning use," Comput. Educ., vol. 47, no. 2, pp. 222-244, 2006.

[36] G. Conole, M. Dyke, M. Oliver, and J. Seale, "Mapping pedagogy and tools for effective learning design," Comput. Educ., vol. 43, pp. 17-33, 2004.

[37] Y.-S. Wang, "Assessment of learner satisfaction with asynchronous electronic learning systems," Inf. Manage., vol. 41, pp. 75-86, 2003.

[38] Y. Lee, K. A. Kozar, and K. R. T. Larsen, "The technology acceptance model: Past, present, and future," Commun. Assoc. Inf. Syst., vol. 12, pp. 752-780, 2003.

[39] R. E. Schumacker and R. G. Lomax, A Beginner's Guide to Structural Equation Modeling. Mahwah, NJ: Erlbaum, 2004.

[40] W. W. Chin, "The partial least squares approach for structural equation modeling," in Modern Methods for Business Research, G. A. Marcoulides, Ed. Mahwah, NJ: Erlbaum, 1998, pp. 295-336.

[41] L. V. Coote, E. J. Forrest, and T. W. Tam, "An investigation into commitment in non-Western industrial marketing relationships," Indust. Market. Manage., vol. 32, pp. 595-604, 2003.

[42] C. Fornell and D. F. Larcker, "Structural equation models with unobservable variables and measurement errors," J. Market. Res., vol. 18, no. 1, pp. 39-50, 1981.

[43] W. Hong, J. Y. L. Thong, W. M. Wong, and K. Y. Tam, "Determinants of user acceptance of digital libraries: An empirical examination of individual differences and systems characteristics," J. Manage. Inf. Syst., vol. 18, no. 3, pp. 97-124, 2002.

[44] A. H. Seyal, M. N. A. Rahman, and M. M. Rain, "Determinants of academic use of the Internet: A structural equation model," Behav. Inf. Technol., vol. 21, no. 1, pp. 71-86, 2002.
[45] K. G. Jöreskog and H. Wold, "The ML and PLS techniques for modeling with latent variables: Historical and competitive aspects," in Systems Under Indirect Observation, Part 1, K. G. Jöreskog and H. Wold, Eds. Amsterdam: North-Holland, 1982, pp. 263-270.

[46] D. Barclay, C. Higgins, and R. L. Thompson, "The PLS approach to causal modeling: Personal computer adaptation and use as an illustration," Technol. Studies: Special Issue on Res. Methodol., vol. 2, no. 2, pp. 285-309, 1995.

[47] J. F. Hair, R. E. Anderson, R. L. Tatham, and W. C. Black, Multivariate Data Analysis. Englewood Cliffs, NJ: Prentice-Hall, 1998.

[48] W. W. Chin, PLS-Graph (Version 3.00, Build 1058), [Computer Software]. Univ. Houston, 2003.

Sergio L. Toral received the B.S. degree in electrical engineering and Ph.D degrees from the University of Seville, Seville, Spain, in 1995 and 1999, respectively.

He is currently a full Professor with the Electronic Engineering Department, University of Seville. His research interests include microprocessor and DSP devices systems, stochastic processing and their industrial applications, and information and communication technologies systems applied to educational environments.

Federico Barrero received the B.S. degree in electrical engineering and $\mathrm{Ph} . \mathrm{D}$. degrees from the University of Seville, Seville, Spain, in 1992 and 1998, respectively.

In 1992, he joined the Electronic Engineering Department, University of Seville, where he is currently a full Professor. His recent interests include microprocessor and DSP devices systems, control of electrical drives and power electronics, and information and communication technologies systems applied to educational environments.

Maria R. Martínez-Torres received the Business Administration and Ph.D. degrees from the University of Seville, Seville, Spain, in 1996 and 2003, respectively.

She is currently a full Professor with the Business Administration and Marketing Department, University of Seville. Her research interests include intellectual capital and knowledge management.

Sergio Gallardo received the Telecommunication Engineering degree in 2002 from the University of Seville, Seville, Spain.

In 2002, he joined the Electronic Engineering Department, University of Seville, where he is an Assistant Professor. He is currently pursuing the Ph.D. degree in information and communication technologies. His current interests include microprocessor and DSP devices systems, information and communication technologies, and virtual-remote instrumentation.

Mario J. Durán received the M.Sc. and Ph.D. degrees in electrical engineering from the University of Malaga, Spain, in 1999 and 2003, respectively.

He is currently an Assistant Professor with the Electrical Engineering Department, University of Seville, Seville, Spain. His research interests include variable speed drives, multiphase machines and VSC modeling, and information and communication technologies systems applied to educational environments. 